\title{
Los intereses, el objeto especulativo de las redes sociales. Una cuestión ética
}

\author{
The human interests, the speculative object of social networks. \\ An ethical issue
}

JORGE MONTESÓ VENTURA*

Resumen: La filosofía siempre ha mostrado preocupación por los intereses humanos en su estudio del conocimiento. Actualmente, con la irrupción de nuevos hábitos sociales promovidos por el uso masivo de redes, esta preocupación está mudando hacia una vertiente de análisis más práctica. Los intereses, rectores de nuestra atención y, en consecuencia, del conocimiento, se han tornando objeto de mercantilización de marcas comerciales. Tal vorágine ha contribuido a que las redes sociales se conviertan en grandes bancos de intereses abiertos al negocio de nuestra intimidad, una conducta que despierta no pocas controversias éticas y que, cada vez más, reclama de nuestro ejercicio.

Palabras clave: Interés, atención, redes sociales, publicidad, pensamiento crítico.

\begin{abstract}
Philosophy has always shown concern about human interests in their study of knowledge. Nowadays, with the emergence of new social customs promoted by the massive use of networks, this concern is moving towards a more practical slope analysis. Interests -guide of our attention and, therefore, knowledge too- have becoming object to commercialization of trademarks. Such maelstrom has contributed to social networks become big banks of interests dedicated to make business with our privacy, a behaviour that awakes many ethical controversies and, increasingly, demands our work.
\end{abstract}

Keywords: Interest, attention, social network, advertising, critical thinking.

\section{Introducción}

Cuando el uso de Internet, posteriormente de las redes sociales, se popularizó, estos se nos presentaron como una insólita, al menos hasta ese momento, oportunidad para el conocimiento. La interconexión de redes aparecía como una gran ventana, aparentemente ilimitada, al mundo de la información. Sin duda esto supuso una gran revolución en el

Recibido: 18/01/2017. Aceptado: 14/09/2017.

* Responsable del departamento de Antropología filosófica del Centre d'Estudis Antropològics ACAF. E-mail: jmonteso.acaf@gmail.com / Líneas de investigación: Antropología filosófica, teoría del conocimiento y fenomenología. Dos publicaciones recientes: Montesó, J. (2016). La atención en el pensamiento de Ortega y Gasset. Castelló: Centre ACAF; Montesó, J. (2017). "La atención como fenómeno de apertura cognoscitiva al mundo. Una aproximación fenomenológica". Contrastes. Revista internacional de filosofia, 22 (2), 107-122. 
campo del conocimiento. Algunos pensadores llegaron incluso a vaticinar cómo este "caos relativo" de información, junto a los ya extendidos mass media, ayudaría a promover cierta emancipación en el ser humano ( $c f r$. Vattimo, 1990, 78): la democratización informativa que posibilitaba la red ofrecía una dispersión de los puntos de vista centrales dando cabida y voz a la diversidad de visiones del mundo, fuesen estas culturas, sub-culturas o minorías subvertidas. Era el momento idóneo para que lo diferente, la pluralidad, emergiese sin reservas. Sin embargo, poco más de veinte años después de su plena irrupción ${ }^{1}$, a la vista de los resultados, algo hace pensar que esta tendencia bien ha durado poco o, al menos, ha tenido un impacto menor del esperado en el proceso de emancipación social.

Las causas de tal desencanto son múltiples y exceden en mucho el motivo del presente artículo, sin remover demasiado es fácil hallar entre ellas elementos propios del mismo sistema de redes pero también elementos educativos, sociológicos, culturales, incluso comerciales que nos afectan como comunidad. De entre ellos, empero, sí nos interesa rescatar uno, uno inherente al sistema y que entendemos fundamental. Ese "caos relativo" del que hablaba Vattimo y que creaba una "niebla informativa" por la que emerger toda pluralidad parece que con el tiempo se fue tornando cada vez más densa debida a la ingente cantidad de información vertida, por lo que la red pronto corrió el riesgo de tornarse un "caos absoluto". La multiplicidad de voces que prometían emerger del ostracismo no tardaron en pisarse unas a otras y tornarse ruido. Frente a ello, para mantener funcional y operativo el sistema, se consideró necesaria la introducción de motores de búsqueda o herramientas de selección de información que agilizasen los procesos de consulta ${ }^{2}$. A nuestro juicio, esto marcó el inicio de un irreversible proceso de tiranización del sistema; un proceso que se agravaría por dos consentimientos públicos que consumarían el fin del ideal de la "ventana de información": el primero, ceder el poder de selección a agentes externos, esto es, aceptar la figura de un gestor de archivo; el segundo, consentir que se hiciese negocio con la información obtenida de nuestras consultas.

Gestionar un archivo, sea de libros o de datos, implica siempre el establecimiento de roles -para el caso, el usuario consultante frente al gestor de la información-, esto inevitablemente quebranta la horizontalidad del sistema y mina la democracia informativa. Ya Derrida $\left(1995^{3}\right)$ asoció la figura del arconte, la figura del gobernante, con la del gestor de archivos. El arconte, archivero gobernante, no solo cumplía el mandato de guardar la información, como custodio de esta era quien gestionaba las consultas del solicitante, para el caso, la satisfacción de los intereses que mueven a los usuarios a realizar sus búsquedas. Es el privilegio inherente a quien guarda y dispone de la información, poder gestionarla. Aparece aquí un sesgo doble en todo acceso al conocimiento que despierta importantes disquisiciones. El primero es inseparable de la labor del gestor de la información, pues este, en tanto agente activo en el proceso de búsqueda, aplica en ella el sesgo que emana de sus propios intereses.

1 Pese a que Internet vio la luz a finales de los sesenta, es con la liberación del código fuente de WorldWildWeb (WWW) en 1993 por parte de su creador Tim Berners-Lee, del CERN, que el fenómeno se convierte en lo que conocemos hoy.

2 El primer motor de búsqueda registrado es Wandex, lo creo el MIT en 1993, pero pronto quedó obsoleto por el crecimiento de la red. Tenemos que esperar a años posteriores para tener grandes buscadores como Lycos (1994) o Altavista y Yahoo (1995) o a 1997 para conocer Google, por citar algunos ejemplos.

3 Derrida, J. (1997), El mal de archivo. Una impresión freudiana, Madrid: Trotta. 
El hecho de no ser el usuario quien realiza directamente la búsqueda sino que lo hace a través de un instrumento mediador, inserta en el proceso un agente al que cede el poder de filtrar o seleccionar, esto es, de eliminar u ordenar arbitrariamente la información solicitada. Se superponen así dos intereses que no siempre deben coincidir, el del usuario y el del gestor de la información. El problema acrece cuando, más allá del sesgo que le es propio, el gestor se sabe en posesión de una mercancía valiosa, esto es, se sabe con la posibilidad de mercantilizar la información recogida a partir de las demandas recibidas -el banco de intereses-, una información fundamental para terceros como empresas u organismos muy dispuestos a pagar por ella. Al sesgo inherente que ya anunciamos se le suma ahora el interés lucrativo. Las objeciones comienzan a ser perspicuas, se alinean frente a nosotros ciertos límites como los que el propio Derrida $(1997,12)$ citaba al hablar de "las relaciones entre lo secreto y lo no-secreto [...], entre lo privado y lo público, ya se trate de los derechos de propiedad o de acceso, de publicación o de reproducción, [...] de clasificación y de puesta en orden". Es más, las objeciones, dados los sesgos apuntados, llegan a poner en duda incluso la validez misma a la respuesta de nuestras consultas.

Este negocio - pues se le puede llamar como tal- eclosiona cuando el comercio, debidas las presiones legislativas, debe hacerse público y contar con el consentimiento explícito del usuario, frente a lo cual, asombrosamente, se ve aceptado por la generalidad de usuarios quienes estiman que "los beneficios percibidos de las redes sociales tienen más peso que los riesgos de la información personal revelada" (Debatin, Lovejoy et al., 2009, 100). A partir de ese momento, los motores de búsqueda y, especialmente, las redes sociales se tornan en afanosos registradores de intereses. Bien sea a través de preguntas directas, del uso de cookies, del control de visitas por cada IP, de los marcadores "me gusta" o emoticonos, etc., las redes registran todos nuestros intereses con la evidente intención de cederlos a intereses comerciales de terceros, empresas u organismos que, a partir de esa información, nos van a poder ofrecer su producto incluso antes de que se exprese nuestra demanda, pues como apunta Lacalle basándose en investigaciones de Marketing Directo $(2011,100)$ "frente a la búsqueda del target de los tradicionales estudios de mercado, Internet ofrece de manera creciente una información más precisa sobre las características y las preferencias de esos nuevos nichos de espectadores". Aquella democrática y prometedora ventana a la información había mudado en escaparate de productos y producciones, la competencia por captar la atención del usuario se convierte así en el motor que mueve Internet.

Ya no es solo que cedamos el poder de selección a un agente externo, sino que ahora la respuesta a nuestro interés se nos da previa a la emergencia del mismo. Mediante algoritmos aplicados a bancos de datos (Big data) -para el caso de intereses- se intenta predecir, con bastante éxito, qué voy a necesitar y se me ofrece con antelación. Hasta tal punto se suplanta la capacidad de afirmación del usuario. La pasividad inducida a la que nos someten está provocando que nuestra capacidad de búsqueda, de selección, nuestra capacidad crítica en su conjunto, quede en cierto modo adormilada por el desuso, lo que puede derivar en efectos comprometedores. Sin tendencia a la exploración y en semejante contexto, nuestro mundo -en tal caso el virtual, pero mundo al fin y al cabo- puede llegar a angostarse hasta el punto de limitarse a aquel que determinados afanes lucrativos deseen que viva, pues compensados mis intereses -antes incluso de que se conviertan en gesto- para qué seguir buscando. Esta actitud nos conduce a perder cierta oportunidad para la exploración y el descubrimiento, 
lo que oculta a nuestros ojos todo atisbo de multiplicidad, a saber, aquello que más allá de nuestras expectativas puede llegar a captar nuestra atención y, en consecuencia, ampliar nuestro conocimiento. Volvemos a caer, en cierto modo, en el horizonte de las utopías -frente al terreno heterotópico que prometía la democratización informativa ${ }^{4}$-, esta vez la utopía hedonista de la plena satisfacción. La diferencia ahora es que todo terreno es válido, nadie restringe el campo porque todo campo se presenta fértil, rentable. El número de escenarios, a diferencia de tiempos pasados, es ahora ilimitado, pero no como un terreno de información libre tal y como esperábamos que fuese, sino como una "trampa de atención", un horizonte estimulante destinado a seducir nuestra atención para que nos quedemos -de grado y sin remisión ( $c f r$. OC, V, 483)- en él y usemos y consumamos lo que allí se nos ofrece. El usuario, sujeto consumidor de información, se ha tornado para los gestores de la red objeto de explotación, su atención les es fundamental y tenerla, como veremos, depende de un buen diagnóstico de los intereses que la espolean, de ahí el cambio en el modelo.

\section{Interés y conocimiento, el papel de la atención}

Como decimos, el objetivo actual que mueve a muchos espacios on-line es la seducción y monopolización de nuestra atención. Captar nuestra presencia y ofrecernos sus productos es la base de su beneficio. Para ello es necesario poseer un alto conocimiento de nuestros particulares intereses, esto es, del motor que mueve nuestra atención. Veamos, a grandes trazos, cómo funciona este mecanismo para comprender mejor el trabajo de las redes sociales a la hora de almacenar intereses ajenos.

El papel que desempeñan los intereses en el conocimiento de la realidad es un tema muy estudiado por distintas disciplinas, sea la filosofía, la sociología, la psicología, pero si estimamos abordarlo desde una perspectiva ética, esto es, teniendo en cuenta el sentido o carácter del comportamiento humano, es la filosofía el camino más hacedero y, en él, pese haber podido abordarlo desde autores tan fundamentales como Kant, Fichte, Husserl, Scheler o Habermas ${ }^{5}$, hemos estimado, para la ocasión, la visión orteguiana del asunto, por ser su estudio no menos destacable y, especialmente, por el acento explícito que sitúa en la “atención”, lo que lo torna muy apropiado para nuestro asunto.

Aunque sin entrar en demasiados detalles, pues ello nos desviaría demasiado de nuestro interés conductor, y cuidando no caer en un excesivo reduccionismo del término ${ }^{6}$, encuadra-

4 Dentro de su idea de multiplicidad abogaba Vattimo por un transito desde las utopías historicistas, regidas por visiones univocistas (mitos en su mayoría), hacia las heterotopías: discursos plurales, múltiples espacios con múltiples dioses. Ver: Vattimo, G. (1990), La sociedad transparente, Barcelona: Paidós, pp. 155 y sig.

5 Para Kant el tema de los intereses resulta fundamental tanto en su crítica a la razón pura como práctica. Tanto Fichte como Scheler tienen sus correspondientes obras donde abordan los intereses: Fichte, J. G. (2005), Ética, Madrid: Akal; Scheler, M. (2001), Ética: nuevo ensayo de fundamentación de un personalismo ético, Madrid: Caparrós. Sobre Husserl vemos muy interesante: Husserl, E. (2008), La crisis de las ciencias europeas y la fenomenología trascendental, Buenos Aires: Prometeo. Del mismo modo, resulta interesante la introducción que Iribarne hace en el mismo abordando meridianamente el tema. Cabría citar también Habermas, J. (1982), Conocimiento e interés, Madrid: Taurus.

6 Para ahondar en la idea de atención en Ortega y cómo esta afecta a su noción de perspectiva ver: Montesó, J. (2016), La atención en el pensamiento de Ortega y Gasset, Castelló: Centre d'estudis antropològics ACAF; Bastida, A. (2005), «Salvación y elegancia de la vida. La Metafísica ética de José Ortega y Gasset». En Llano 
remos la idea de atención orteguiana a partir de una conferencia que el madrileño profirió en junio de 1927 en la Residencia de Estudiantes de Madrid, "Estudios sobre el corazón"7. En ella, Ortega, en línea a las objeciones husserlianas al positivismo cientificista, aludía a la relación que el corazón (el sistema de intereses y preferencias en su generalidad) mantiene con la cabeza en todo proceso de conocimiento de la realidad. Defendía que, en tal ecuación, tradicionalmente se había concedido toda primacía a la cabeza, a la razón, según lo cual, para conocer la realidad, debía ser el intelecto quien llevase la iniciativa, siendo el elemento emotivo un efecto o respuesta a tal aprehensión intelectiva. De este modo, podríamos afirmar que solo alcanzábamos a estimar aquello que, ya de antemano, formase parte de nuestro conocimiento. Sin embargo, para el madrileño, la experiencia no parecía conducir al mismo orden, sino al contrario. Para Ortega, las personas no somos seres pasivos que nos situamos frente una realidad que nos inunda para luego interpretarla, al contrario, en nuestra interacción con el mundo, salimos tras un interés, somos seres interesados, sujetos agentes que buscamos activamente en el entorno aquello por lo que sentimos cierta predilección, o lo que es lo mismo, se podría decir que todo lo que de algún modo está implicado en nuestro plan de vida, nos afecta, nos interesa. Hay, tras el foco atencional, algo que nos mueve a buscar, un motivo, un interés previo mediante el cual el corazón "busca para que el entendimiento encuentre" (OC, VIII, 326). Diríamos que, para Ortega, según se observa en el comportamiento humano, es el corazón el motor del conocimiento, un corazón que dirige nuestra atención a través de los sentidos para alcanzar cognoscitivamente determinados aspectos de la realidad. De aquí que "un mismo trozo de tierra se multiplica en tantos paisajes cuantos sean los hombres o los pueblos que por él pasan" (OC, IX, 161). Ortega pretende enfatizar cómo los humanos no somos impávidos seres racionales, sino seres racionales colmados de intereses. Bruscamente, podríamos decir que los humanos buscamos en la realidad, pretendemos conocerla, tras el empuje del corazón, de nuestro sistema de intereses. De ahí la importancia en su filosofía de la idea de perspectiva, pues nuestro conocimiento y relación con la realidad, nuestra co-existencia, se da en cada ocasión concretada a un conjunto determinado de aspectos interesantes de esa misma realidad compartida, pues cada cual centrará su atención allá donde sus intereses le lleven en cada caso, incluso en cada momento, desestimando el resto. Así es cómo, grosso modo, esbozamos nuestra perspectiva de las cosas, mediante una composición de atenciones y desatenciones. La atención, dice el propio Ortega, es "una preferencia anticipada que subjetivamente otorgamos a unas cosas en prejuicio de otras" (OC, III, $895^{8}$ ), esto es, lo que vemos, fundamentalmente, lo vemos porque lo atendemos y atendemos algo porque de todo lo posible, de todo el horizonte perceptivo, ese algo nos interesa y provoca que dirijamos sobre ello nuestra atención, lo fijemos en el centro de nuestra mirada y lo acentuemos sobre el resto de elementos pudiendo ser

\footnotetext{
Alonso, F. H. Y Castro Sáenz, A. (eds.). Meditaciones sobre Ortega y Gasset, Madrid: Ed. Tébar, pp. 55-108; García Alonso, R. (1997), El náufrago ilusionado: La estética de José Ortega y Gasset, Madrid: Siglo XXI; y Carpintero, H. (1983), «Procesos psicológicos y situación histórica en el pensamiento de Ortega», Psicopatología, ${ }^{\circ} .3$, vol. 2, pp. 157-170; (1990), «Ortega y la psicología: el caso de la atención», Revista de Occidente, $\mathrm{n}^{\circ} .108$, pp. 49-60; y (2000), Esbozo de una Psicología según la razón vital, Madrid, España: Real Academia de Ciencias Morales y Políticas.

7 Recogida en el tomo IV de las Obras completas (OC, IV, 80).

8 La deshumanización del arte e Ideas sobre la novela (OC, III, 846). 1925.
} 
así objeto de nuestro conocimiento. El conocimiento es así, pues, producto de un imperativo de luz, de un proceso de des-cubrimiento posibilitado por "una linterna que necesita ir dirigida por una mano y la mano necesita ir movilizada por un afán preexistente [...] solo se encuentra lo que se busca" (OC, VIII, 325-326 $)$. Esta podría ser, mutatis mutandis, la piedra de toque que explique el modo de proceder, entre muchos otros sistemas, de la mayoría de espacios on-line que venimos analizando -"solo se encuentra lo que se busca"-, para lo cual les apremia conocer al máximo los intereses que nos mueven.

El propio Ortega -gran activo en el estudio de la atención- advertía de los riesgos a los que nos exponemos cuando esta atención queda desmesuradamente seducida por determinados estímulos, riesgo al que nos exponemos cuando visitamos determinadas redes sociales, las cuales ceden espacios privilegiados a anuncios publicitarios con la intención de monopolizarla. Aunque Ortega estudiase esta anomalía atencional a propósito del "enamoramiento", el mecanismo equivale al aquí anunciado -en su momento, el mismo Ortega indicó cómo este actuaba igual en procesos tan dispares como el misticismo, la hipnosis, e incluso el narcisismo ${ }^{10}$. Decía el madrileño que el enamoramiento es "atención anómalamente detenida en otra persona" (OC, $\mathrm{V}, 480)$, una retención producida por un efecto de seducción o fascinación hacia ella. Cuando estamos enamorados, todo nuestro anhelo se dirige a la persona amada, deseamos su presencia pues ella provoca en nosotros cierta sensación de plenitud; nuestro interés se ve, pues, absorbido por dicho ser y su contemplación, la confirmación de su presencia provoca en nosotros cierto estado de placer, de satisfacción, lo que mantiene cautivada nuestra atención de grado, pero sin remisión (cfr. OC, V, 483).

En un estado "normal" de la atención, podríamos decir que nuestra conciencia se halla constantemente ocupada por un conjunto plural de elementos que desfilan en el horizonte vivido. Nuestra atención recorre la realidad en torno aprehendiendo determinados elementos de esta en un itinerario de acentos, deteniéndose en ellos más o menos según el valor vital que les concedamos, al fin y al cabo eso es la curiosidad, ansia de vida (cfr. OC, V, 190). Así es cómo conforma cognoscitivamente el mundo el ser humano, movido por su curiosidad/ necesidad, hallando en el horizonte aquellos estímulos que responden a sus intereses. Pero en un estado de enamoramiento o de seducción, cuando nuestro interés se ve constreñido a la persona amada $-\mathrm{O}$, en el caso de las redes sociales, cuando determinados estímulos del campo, que ya se saben interesantes de antemano, están intencionadamente ubicados en dicho horizonte-, nuestra atención corre el riesgo de no llegar a recorrer el campo en su integridad. Al contrario, muy posiblemente quede esta fijada sobre el elemento interesante $\mathrm{y}$, al sentir satisfecho el motivo de su examen, detendrá ahí su curso exploratorio, interrumpiendo el reconocimiento del resto del entorno. La consecuencia, como ocurre en el enamoramiento, también en nuestro navegar por las redes, es que muchos elementos del horizonte corren el riesgo de quedar desatendidos, ignorados. Si tal proceso se perpetuase en el tiempo, si nuestro mundo -entiéndase virtual- se viese constantemente inundado de figuras interesantes situadas estratégicamente en un primer plano perceptivo para ser captadas de inmediato, "el objeto anómalamente atendido [...] ocuparía todo ámbito de nuestra mente y sería [...] todo

9 ¿Qué es filosofia? (OC, VIII, 235). 1929.

10 Sobre la hipnosis y el misticismo ver Estudios sobre el amor (OC, V, 485 y sig.); sobre el narcisismo, ver «Intimidades» (OC, II, 728). 
ese mundo" (OC, $\mathrm{V}, 479)$, correríamos así el riesgo de reducir dicho mundo a él -entiéndase por él: anuncios-. Con el interés colmado no habría ya necesidad de seguir explorando, más allá del anuncio bien situado y ajustado a nuestros intereses, el resto dejará de ocuparnos y preocuparnos, de modo que lo patente sería todo lo necesario y, en consecuencia, todo lo consciente. El resultado derivaría paulatinamente en un angostamiento de nuestro mundo por un consecuente "angostamiento y relativa paralización de nuestra vida de conciencia" (OC, V, 478), de una capacidad exploratoria que dejaría de ser necesaria. La lógica es sencilla, estas plataformas seducen nuestra atención ofreciendo aquello por lo que sentimos o podemos llegar a sentir interés $y$, en un mundo aparentemente tan hacedero donde hallo lo que me interesa con total facilidad e inmediatez, para qué seguir buscando, ¿qué necesidad hay de usar mi capacidad crítica, mi capacidad de comparar y evaluar? He aquí el riesgo y el motivo de nuestra reflexión, la posibilidad de que, si esta tendencia se convierte en hábito -como parece estar pasando en muchas redes sociales-, acabe por alterar o degenerar nuestra disposición y actitud en el mundo, esto es, nuestro modo de ser en tanto ser-en-elmundo. Como hemos anticipado, nuestra tendencia hacia el mundo es de ocupación, pero también lo es de preocupación, la nuestra es una salida proyectiva, vocacional, partimos con la intención de ejecutar un plan de acción que responde a todo un proyecto de vida. En esa preocupación, previa a la acción, generamos una estrategia con la que alcanzar aquello que necesitamos para nuestro desarrollo, contemplando los estímulos que despertarán nuestro interés. Si aprendemos a obtener de inmediato y con un solo clic lo que necesitamos, lo que nos interesa, la distorsión, o el riesgo de caer en ella si no actuamos al respecto, está servida. Nuestra estrategia de exploración puede llegar a restringirse a una mera consulta y si, como el enamorado, nos rendimos al angostamiento, esto es, si acabamos creyendo que el mundo en torno se reduce a lo que nos ofrece ese espacio web, puede que no lleguemos nunca a comparar productos, a valorar críticamente el servicio ofrecido (pues nuestro escaparate quedará muy reducido) y quememos todos nuestros recursos -económicos- en los anuncios allí vertidos. En definitiva, puede que nos conformemos con consumir aquello que nos ofrecen sin mayor espíritu crítico, inicialmente por comodidad, quizá al fin por el desconocimiento de que, más allá de esa ventana virtual que busca por nosotros, existen muchos más productores que pueden ofrecernos mejores o más ajustados productos -al final, tan enamorados, puede que nos estemos quedando con una novia mediocre por no haber salido a ver más mundo-.

Visto, pues, el riesgo que, como usuarios, corremos al acceder al juego de quienes buscan dominar nuestra atención así como el mecanismo por el que la cautivan, nos queda ahora abordar el objeto de análisis antes de revisar cómo y quiénes parasitan nuestra intimidad y qué podemos hacer al respecto. Veamos, pues, qué es el interés.

\section{El interés, componente rector del conocimiento}

Para conocer el significado de qué es el interés y qué función desempeña en los procesos de conocimiento, entendemos preciso revisar -aunque por cuestión de espacio lo hagamos muy someramente dejando la puerta abierta a que sea el lector quien rastree la bibliografía anunciada-, algunos de los más destacados estudios a tal efecto. Las disquisiciones, aunque en la Modernidad sufrieran un enérgico repunte, no son para nada recientes, 
casi diríamos que son tan antiguas como la filosofía misma -recordemos la oposición entre doxa y episteme-. En la Modernidad, empero, la discusión sobre la participación o no de los intereses en el proceso cognoscitivo se ve inmersa en la oposición entre los modelos objetivistas frente a los trascendentalistas recorriendo, con ellos, la columna vertebral de la disciplina. Husserl, en su Krisis -donde realiza un sugerente recorrido histórico de esta oposición-, apunta cómo la consolidación del positivismo como adalid del pensamiento científico provoca que el mundo de la vida, allí donde enraíza lo particular e interesado, sucumba a un ostracismo insólito hasta entonces. Como paradigmático cita el caso de Galileo, con quien arranca, dice, una "sustitución de la naturaleza intuida, pre-científica, por la naturaleza idealizada"11 en el conocimiento de la cual los intereses cotidianos resultan totalmente excluidos. Galileo y la tendencia positivista, afirma el moravo, estarán muy presentes en Descartes, quien verterá el modelo idealista sobre todas las ramas del pensamiento. Será desde este, y a través del empirismo inglés, que el modelo se perpetúe hasta Kant ${ }^{12}$, consolidando una tendencia a desatender a los intereses en el proceso del conocimiento o, en el mejor de los casos, a considerarlos algo "añadido" o ajeno al aparato cognoscitivo ${ }^{13}$.

En Kant, empero, se intuye cierto giro o replanteamiento de la cuestión. En su filosofía aparece la idea del "interés de la razón". Al cuestionarse el problema de la libertad, Kant se ve abocado a aceptar cierta causalidad en la razón para que esta devenga práctica, una idea que implícitamente alude a un interés o elemento generador. No obstante, a pesar de contemplar la idea del interés, su análisis permanece anclado a una acepción estrictamente cognoscitiva del término, a un interés puro práctico, que deja al margen a los intereses sensibles, es decir, a una parte fundamental del concepto que pretendemos asir, con lo que el término continuaría demasiado restringido en Kant. Habermas, en su análisis del término ${ }^{14}$, reconoce cierta ambigüedad en las conclusiones del filósofo de Königsberg, una imprecisión que, posteriormente, llevará a Fichte a abrir en firme la puerta del conocimiento al interés, pues "el interés práctico de la razón solo podría asumir el papel de un interés rector del conocimiento [...] si Kant tomara en serio la unidad de razón teórica y razón práctica”, cosa que no despliega pero que, como indica él mismo, sí consuma Fichte. Este "concibe el acto de la razón [...] como una actividad reflexiva"15 de modo que la razón cae bajo el predominio de la intención práctica, para el caso, en la forma de autorreflexión. De este modo, el interés más elevado y razón de todo interés será el interés por nosotros mismos en la emancipación y autonomía del yo ${ }^{16}$, que se manifiesta en la autorreflexión. Reconocimiento tal permite que, al fin, el interés deje de presentarse como algo "añadido" al conocimiento y se dé, ahora sí, como un firme y aceptado elemento rector.

Esta apertura es apuntada también por Pierce y Dilthey en sus distintos campos de estudio (ciencias de la naturaleza y del espíritu). Estos autores, al centrar su análisis en contextos

11 Husserl, E. op. cit., p. 93.

12 Ibid., §8-27.

13 López Molina, A. M. (2002), «Autorreflexión e interés emancipatorio en J. Habermas», En A. Domínguez. Vida, pasión y razón en grandes filósofos, Cuenca: Ed. Univ. Castilla-La Mancha, p. 371.

14 Habermas, J. op. cit.

15 Ibid., p. 207.

16 Ver en Fichte, J. G. op. cit. 
vitales fácticos donde el conocimiento se da bajo determinadas condiciones culturales ${ }^{17}$, se ven empujados a reconocer ese poder rector del interés, pues los modelos positivistas no responden a las necesidades metodológicas de sus realidades de estudio. Sucede, empero, que su concepto de interés, pese a quedar firmemente vinculado al conocimiento, sigue muy restringido a una noción cognoscitiva del mismo, a un interés racional que no alcanza a superar la refutación psicologicista posterior que alumbra el neo-positivismo ${ }^{18}$. Para que el interés sea contemplado en su compleción es preciso abandonar los terrenos idealistas y las herencias positivistas para hacer pie en el mundo de la vida, volver a la naturaleza pre-científica y replantear el estudio del conocimiento, esto es, como apuntaría Husserl, cuestionando todo lo obvio. Ello acontece precisamente con la fenomenología, en especial con el filósofo moravo.

Para Husserl, el conocimiento, sea o no científico, nunca es extraño al mundo de la vida, al contrario, necesariamente enraíza en él, se origina en él. Para el fenomenólogo, el interés es "el motor de la acción, lo que pone en marcha el acontecer orientado a la meta. Los intereses forman parte de la estructura habitual de la personalidad [...], los propósitos actuales de la actividad yoica" (Iribarne, 2007, 112) entre los que se incluye el conocimiento. La identidad de la persona se organiza en torno a sus intereses, los cuales apuntan la meta a la que dirigirse. Como motores de la acción, también lo son de la percepción, por lo que toda nuestra experiencia y conocimiento del entorno vendrá relacionada con ellos. Nuestra representación del mundo se reconstruirá, pues, constantemente y según la actualización de nuestros particulares intereses ${ }^{19}$, que mudan en función de las variaciones en el entorno, del proyecto de vida, etc. El conocimiento, pues, actúa siempre en y desde el mundo de la vida según los intereses que de ella se despierten. En esta línea, hemos aludido ya en este artículo al interés como a esa mano que mueve la linterna, una metáfora que Ortega adquiere de Scheler y que bien describe lo que el interés representa para la fenomenología.

En suma, el interés se plasma o manifiesta en el gesto que mueve al sujeto hacia algo. Este, en su capacidad de intuir la realidad, ejerce un acto en el que ve implicados sus intereses. El primado de unos sobre otros se torna así motor para el descubrimiento (Alétheia) de elementos hasta entonces desapercibidos o, mejor dicho, desatendidos. Así, podríamos decir que el interés es la inclinación del ánimo hacia algo; es la tendencia que nos arroja al mundo, un gesto centrífugo que va del sujeto al objeto en flujo constante ${ }^{20}$. El interés, pues, es el nombre que damos a la reacción sistémica del cuerpo humano que se activa frente a la exigencia de una necesidad, no como un mero impulso instintivo, pues no es simplemente pulsión o afecto -los pulsos avivan el interés pero en él intervienen otros elementos biográficos-, tampoco simple gesto cognitivo, sino que el interés emerge por la intervención de "la constelación íntima de nuestras necesidades, deseos, apetencias, conveniencias vitales, preferencias, sentimientos, amores; en suma, todo eso que Ortega designa [...]: corazón"

17 Habermas, J., pp. 194-198.

18 Ibid., p. 193.

19 Iribarne, J. (2007), De la ética a la metafisica en la perspectiva del pensamiento de Edmund Husserl, Bogotá: San Pablo, p. 114.

20 En Pfänder, A. (1913), Zur Phänomenologie der Gesinnungen, Jahrbuch für Philosophie und phänomenologische Forschung, Hale. 
(Rodríguez Huéscar, 1985, 102). Diríamos pues que, para nosotros -y con ello dejamos por definido el concepto-, el interés es el sentir de una tendencia que responde a una combinación integral de impulsos en armonía o conciliación con todo un proyecto de vida.

Pues bien, esta constelación que agita nuestros intereses y participa de la conformación de lo que el sujeto es en tanto ser histórico es, pues, el objeto de interés -valga la redundancia- de quienes pretenden captar nuestra atención y lucrarse con ello. Analicemos su proceder tal y como era nuestro cometido.

\section{Bancos de intereses, el caso Facebook}

Desde los afanes comerciales transferidos fundamentalmente a las redes sociales se pretende alcanzar el máximo conocimiento de nuestra intimidad, de nuestro sistema de intereses y preferencias, procurando hacer de esta un objeto dispuesto para el mercadeo. Esto se consigue y fundamenta en que la estructura de las redes sociales está destinada, y permite, que sus usuarios hagan de lo íntimo algo externo y, en consecuencia, algo aprovechable. Objetivada y exhibida nuestra intimidad, solo queda recoger y almacenar. Para ello se crean lo que hemos llamado bancos de intereses, esto es, grandes bancos de datos -Big data- en los que se allega toda la información relacionada con los intereses y usos y costumbres de los usuarios de redes sociales y otros labrantíos; bancos, en muchos casos, perpetuos, esto es, donde la información queda almacenada ad aternum, con todas sus implicaciones morales y legales ${ }^{21}$. Por ello, la controversia no yace tanto en el hecho de exhibir nuestra intimidad $\mathrm{y}$ de que esta quede registrada en nuestros muros o perfiles -lo cual es un gesto libre y, de algún modo, quizá hasta emancipador-, sino por el hecho de que, una vez exhibida, no seamos informados de su objeto último o de a quiénes y para qué se les entrega, y hasta cuándo. Esto nos introduce de lleno en terrenos legislativos ${ }^{22}$, lo cual excede el motivo del artículo, pero no deja de reincidir en las disquisiciones éticas que venimos planteando sobre el modo en que se nos objetiva, a través de la mercantilización de nuestra intimidad, y cómo la información obtenida de una manera -como ahora veremos- más o menos opaca, se nos devuelve reconstituida en forma de anuncios publicitarios.

Para ahondar en el asunto, entendemos necesario poner cierto acento en el modo en que dicha información se capta, pues ahí es donde, en tanto usuarios -esto es, sujetos activos y libres-, podemos interceder directamente apelando a la responsabilidad y criticismo de cada cual. Estos canales de captación son diversos y sumamente cambiantes, lo que forma parte ya de la propia estrategia de éxito, pues la arquitectura de estas páginas y las herramientas para el control de la información utilizadas albergan una intencionada complejidad estructural con la que parece que se pretenda abrumar al usuario y disuadirlo, por indefensión, en su afán de conocer sus entresijos, primera objeción notable. A partir de aquí, advertimos dos modos fundamentales de recogida, uno indirecto, que se conforma a través del historial de

21 Sobre el derecho al olvido en internet existe jurisprudencia en favor de particulares que han reclamado que la información relativa a su persona quede eliminada de los motores de búsqueda. Sobre ello ver: www.agpd.es/ portalwebAGPD/CanalDelCiudadano/derecho_olvido/index-ides-idphp.php. (12/09/2016).

22 Para consultar la normativa vigente sobre privacidad on-line visitar el espacio de la Agencia Española de Protección de Datos: http://www.agpd.es/portalwebAGPD/canaldocumentacion/legislacion/index-ides-idphp.php. $(12 / 09 / 2016)$. 
nuestras búsquedas; el otro, mucho más intrusivo e inmediato, y que necesita, sin embargo, de la complicidad del usuario quien, por extraño que pueda parecer en este contexto, frente a los beneficios sociales que le reporta exhibir su intimidad en las redes, acaba consintiendo, en el peor de los casos sin ser consciente o reparar al menos en las consecuencias ulteriores.

El primer modo de captación, el indirecto, respondería muy bien al apotegma orteguiano del "dime lo que atiendes y te diré quién eres" (OC, V, 479). La red tiene una posición privilegiada para registrar todas nuestras miradas y tras ellas obtener una jugosa información sobre nuestros intereses. La atención es uno de esos gestos de emergencia vital que se engendran en el fondo más hondo del sujeto. Como decimos, miramos lo que nos interesa ver, aquello que responde a nuestros apetitos, a nuestras necesidades, a nuestras motivaciones. Tales emergencias, manifiestas por la saeta atencional, acaban por prorrumpir al exterior en busca del objeto interesante y, para beneficio de estos espacios, en su salida, la saeta arrastra con ella sedimentos del alma de la cual proviene, indicadores del sistema de preferencias e intereses que la mueven. Por ello es muy viable que, a través de un minucioso estudio de lo que cada cual atienda, podamos llegar a advertir los retazos de alma que lo impelen; esos restos que la atención desvela al exterior y que permiten obtener a estos comerciantes de intereses un material de especial provecho para el conocimiento esencial del sujeto y de su disposición a movilizar sus recursos. La atención, pues, es uno de esos "escotillones y rendijas por donde deslizarse a lo profundo de la persona" (OC, V, 502), todo aquello que atendamos, para las redes sociales, será un potencial objetivo de gasto, un campo de negocio para con terceros, un gesto que no pueden dejar al azar.

Por ello, la red registra todo movimiento que indique cierta voluntad atenta, bien sea a través de la propia actividad en la página, a través de otras páginas visitadas -Facebook, por ejemplo, hace seguimiento a través del Share, de los Like y del llamado Facebook pixel ${ }^{23}-$, también de las búsquedas acumuladas en motores, de nuestros check-in, de la ubicación geográfica de nuestra dirección IP, incluso a través de datos facilitados previamente a una determinada empresa y que esta puede enlazar con tu perfil. Así es cómo redes como Facebook pueden realizar un seguimiento exhaustivo de nuestros movimientos por la red sin ninguna participación activa por nuestra parte, únicamente siguiendo las huellas de nuestras miradas, de aquello a lo que atendemos. Con ello obtienen datos suficientes para establecer patrones de comportamiento que, cruzados con nuestros datos de perfil, ofrecen una información sociológica de alto valor para cualquier tipo de marca comercial. Del mismo modo sucede con el reconocimiento facial que, a través nuestra aparición en fotografías, nos ubica en escenarios determinados que ofrecen cantidad de información sobre nuestros gustos y costumbres.

El segundo modo de acopio es mucho más directo e intrusivo y, como decimos, cuenta con cierta concesión por parte del usuario. Este alude a la pregunta directa, esto es, a la recogida de información a través de cuestionarios sobre aspectos biográficos, tendencias, gustos, a partir de la etiquetación en fotos y, como es obvio, de la información del perfil. Como hemos apuntado anteriormente, nuestros intereses, allí donde depositamos nuestra atención, están directamente relacionados con nuestro proyecto de vida, con lo que somos, con lo que pretendemos ser. Nuestras elecciones, de algún modo, son vocacionales, son un gesto proyectivo dirigido hacia un futuro pre-tendido, hacia la consecución de aquello que

23 El Facebook pixel es una aplicación que mide la efectividad de los anuncios emitidos en su red. 
nos permita vivir. De aquí que conocer nuestra biografía dé claras pistas de nuestras futuras necesidades, de cuáles vayan a ser nuestros intereses, de hacia adónde, de entre un sinfín de proposiciones comerciales, tenderá nuestra atención.

En esta modalidad, de nuevo Facebook se erige como el paradigma del coleccionista. No es casualidad, ya que es la red social con más usuarios del mundo -con alrededor de 1710 millones de usuarios mensuales en el segundo trimestre de 201624-. En España, según estudios de IAB Spain ${ }^{25}$, en el presente año el $81 \%$ de los internautas españoles de 16 a 55 años han usado redes sociales, de los cuales la mayoría elige Facebook. Facebook es también, según este estudio, la red más utilizada para seguir marcas comerciales (un $81 \%$ de usuarios frente a un $25 \%$ que usa twitter), lo cual no parece casualidad.

Esta información directa que obtiene Facebook se reúne en un inventario que casi alcanza el centenar de ítems, un inventario que, en favor de una nueva política de transparencia que la red social ha emprendido recientemente, se pueden consultar en su sección Aboud Facebook $A d s^{26}$. Como de ella se extrae, muchos de los ítems están directamente relacionados con nuestros potenciales intereses. Así, se pretende información sobre nuestras propiedades inmuebles o vehículos como su antigüedad, marca o determinadas características que evidencien preferencias a tal efecto; también hacen acopio del tipo de ropa que solemos escoger, de las bebidas y comida favoritas, de viajes o turismo reciente; preferencias en medios de comunicación, en juegos y videojuegos y, en general, de cuáles son nuestros intereses en las diferentes áreas de consumo habitual. Otros ítems resultan más tangentes al interés mismo -al interés consciente- y lo pretenden a través de nuestros hábitos: así se busca saber en qué momento del año gastamos más en ropa u otros géneros como productos de belleza o medicamentos; qué tipo de restaurantes frecuentamos, qué tiendas, si efectuamos o no compras on-line; pero también les interesa conocer nuestro banco o caja de ahorros, si tenemos abiertas líneas de crédito, uso y tipo de tarjetas y todo lo referente a paquetes financieros. Por otro lado se pregunta por el sistema operativo que usamos, el navegador, e-mail, móvil. Finalmente, si con ello no se tuviese ya bastante información sobre nuestros intereses y planes de consumo, nos interrogan e investigan sobre aspectos de nuestra actual situación vital, eventos biográficos tanto del propio usuario como también de usuarios allegados a nosotros: hablamos de cumpleaños y celebraciones; gastos relacionados con hijos, con mascotas; formación académica y profesional, si somos estudiantes, empresarios, en tal caso, número y perfil de trabajadores; también de nuestra residencia habitual o si existe otra y cabe posibilidad de cambio. En suma, se pretende -y consigue- una cantidad ingente de información sobre quiénes somos, incluyendo en ello nuestra circunstancia, con la intención de colectar todo lo que pueda estar relacionado con nuestros intereses actuales; ni más ni menos que 98 ítems directa o indirectamente relacionados con nuestro sistema de preferencias e intereses que posibilitan a los bancos de datos, una vez cruzados con nuestros perfiles, una instantánea muy detallada de nuestros probables hábitos de consumo. Obviamente todo un yacimiento para las empresas destinadas a tales negocios a las que, entidades como Facebook, nunca han tenido la intención de ignorar.

24 Informe de resultados del segundo trimestre de 2016 de la compañía Facebook: https://investor.fb.com/investornews/press-release-details/2016/Facebook-Reports-Second-Quarter-2016-Results/default.aspx. (12/09/2016).

25 iabspain.net/wp-content/uploads/downloads/2016/04/IAB_EstudioRedesSociales_2016_VCorta.pdf

26 Ver en: www.facebook.com/ads/about/. (12/09/2016). 


\section{Frente a ello...}

Las cuestiones, sobre todo éticas, aquí surgidas no son para nada exiguas. Con la popularización de estas plataformas se nos presenta un largo trabajo de reflexión y, fundamentalmente, de actuación que no podemos desestimar. Son cuestiones que deben plantearse, obviamente, desde un enfoque sistémico, pero en todas sus proposiciones la ética, como disciplina, tiene mucho a aportar. Un foco de actuación se abre en el asesoramiento jurídico o alumbramiento de buenas prácticas. En esta línea ya hay comisionados, como la Oficina del Comisionado de Protección de datos de Irlanda, que frente a estas "amenazas" ha planteado una serie de recomendaciones ${ }^{27}$ más que interesantes entre las que encontramos demandas al respecto de la aplicación de mecanismos de información a usuarios sobre cómo es usada y compartida con terceros su información; la actualización de políticas de uso y privacidad; transparencia y control de la provisión de datos personales; supresión de la información de usuarios y no usuarios a través de plugins; o mayor transparencia y controles para el uso de los datos personales con fines publicitarios. En definitiva, una serie de buenas prácticas que promuevan el dictado de leyes que ofrezcan la necesaria protección jurídica a los usuarios sobre la libre gestión de su intimidad. Ahora bien, a pesar de estas loables propuestas, los avances siguen siendo exiguos, principalmente por la capacidad cambiante de las plataformas digitales que obliga a estar constantemente atentos a sus estrategias de captación de información y a responder en consecuencia.

Para ello entendemos imprescindible un segundo nivel de intervención orientado a establecer parámetros éticos y respetuosos con los usuarios en el diseño mismo de estas redes sociales; parámetros que hagan de estas un espacio seguro y de óptimo control de la información donde los usuarios puedan tener la certeza, en tiempo y forma, de que su información no será utilizada sino para fines a los que él mismo dé consentimiento explícito y demostrado de que así lo hace. Una buena base de partida para el diseño de estas plataformas la podríamos hallar en las ya existentes en el campo biomédico, esto es, en las bases de datos que albergan información médica para el que existen códigos rigurosos y probados como el Código ético de la IMIA para profesionales de la información de la salud ${ }^{28}$. Aunque, inicialmente, el ámbito de aplicación diste de ser equivalente, los principios éticos que rigen estas bases de datos bien podrían generalizarse a las redes sociales. Según sus principios ${ }^{29}$, las plataformas

27 Oficina del Comisionado de Protección de datos de Irlanda. (2012). Report of Data Protection Audit of Facebook Ireland Published dataprotection.ie/viewdoc.asp?DocID=1175. (12/09/2016).

28 Código de Ética de IMIA para Profesionales de la Información de la Salud. En: http://www.imia.org/pubdocs/ Spanish_Translation.pdf (12/09/2016).

29 1. Principio de Privacidad y Disposición de la Información. Todas las personas poseen el derecho fundamental a la privacidad y, en consecuencia, a ser informadas y ejercer el derecho de autorizar la recolección, almacenamiento, acceso, uso, comunicación, manipulación y disposición de la información sobre sí mismas. 2. P. de Transparencia. La recolección, almacenamiento, acceso, uso, comunicación, manipulación y disposición de información personal debe ser revelado en tiempo y forma apropiados al sujeto de esos datos. 3. P. de Seguridad. Todas las personas tienen el derecho a que la información que ha sido legítimamente recolectada sobre sí, sea debidamente protegida, mediante todas las medidas disponibles, razonables y apropiadas tendientes a evitar pérdidas, degradación, así como la destrucción, el acceso, uso, manipulación, modificación o difusión no autorizada. 4. P. de Acceso. El sujeto de un registro electrónico tiene el derecho de acceder al registro y a exigir la exactitud del mismo con relación a su precisión, integridad y relevancia. 5. P. de Resguardo Legí- 
sociales deberían tener una estructura que, inicialmente, procurase ya por la protección de la privacidad del usuario y solo a posteriori, con el explícito consentimiento de este, debiera permitirse el uso interesado de su información. Según los principios que plantea la IMIA, si los aplicásemos a las redes sociales, deberían estas ofrecer vías sencillas y directas -lejos de la compleja infraestructura a la que nos vienen acostumbrando- por las que todo usuario pudiese, a tiempo real, consentir explícitamente que su información vaya a ser usada por terceros, y no por terceros anónimos, sino explicitando en cada caso qué empresas, organismos o instituciones solicitan acceso a su información y con qué fin lo hacen o, en su defecto, informar en el mismo proceso de alta en la red social de las empresas, organismos e instituciones con las que se trabaja y a las que se les podrá facilitar dicha información. Toda alteración de este "contrato" inicial, debería ser informado al usuario. Solo así, entendemos, el consentimiento o revocación será plena y la libertad del usuario se mantendrá preservada. El sujeto, pues, debería ser informado y ejercer el derecho a la recolección y almacenamiento según el principio de privacidad y disposición de la información, pero también debería cumplirse el principio de transparencia según el cual el usuario debe tener conocimiento de quién accede a ella y, según los principios de acceso y resguardo legítimo, poder o no acceder a semejante concesión y, en tal caso, negociar los parámetros de la misma. Pero con esto volvemos a la legislación. Para que estas aportaciones sean consideradas por las empresas que sustentan las redes, dado el lucrativo negocio en el que se hallan inmersas, deberían ser coaccionadas por una legislación internacional firme y unívoca que preserve los derechos de los usuarios, de otro modo, difícilmente veremos cambios semejantes.

Cabe decir, como no podría ser de otro modo, que esta protección jurídica y regulación de la estructura de las redes sociales no puede sino ir acompañada, como bloque imprescindible, de una necesaria concienciación y apelación a la responsabilidad individual de cada sujeto, para lo cual hay que educar: tercera vía de intervención donde la ética debe tener presencia. Frente a esa manipulación intencionada a la que se someten nuestros intereses, la mejor apuesta que desde la ética podemos lanzar es la de incidir, aún más si cabe, en la estimulación y apelación al pensamiento crítico. Frente a la inundación de elementos interesantes y el consecuente angostamiento de nuestro horizonte vivido, el usuario debe, ya no aprender a dudar, sino acceder a tales plataformas provisto de una actitud crítica, con la disposición abierta y tendente a la exploración, al conocimiento integral del horizonte perceptivo con una exigencia rigurosa en sus elecciones que, en definitiva, demuestre su emancipación autónoma como individuo. Como educadores, debemos procurar que el usuario tenga la capacidad y las herramientas necesarias para no ser presa de la estimulación publicitaria y de productos culturales y despierte la necesidad de buscar activamente en el entorno, haciendo

\footnotetext{
timo. El derecho fundamental sobre el control de la recolección, el almacenamiento, acceso, uso, manipulación, comunicación y disposición de la información personal, está condicionado sólo por las necesidades legítimas, apropiadas y relevantes de información en una sociedad libre, responsable y democrática, así como por los correspondientes derechos iguales y competentes de otras personas. 6. P. de la Alternativa Menos Invasora. Cualquier acción legítima que deba interferir con los derechos del individuo a su privacidad o al control sobre la información relativa a ésta, según lo establecido en el Principio $\mathrm{N}^{\circ} 1$; deberá sólo ser efectuada de la forma menos invasora posible, tal que garantice el mínimo de interferencia a los derechos de las personas afectadas. 7. P. de Responsabilidad. Cualquier interferencia con los derechos de privacidad de un individuo o del derecho de tener control sobre la información relativa a su persona, debe ser justificada a tiempo y de manera apropiada ante la persona afectada.
} 
acopio de suficientes propuestas que le ofrezcan la alternativa necesaria para, efectivamente, realizar una elección libre y autónoma. Para ello, claro está, el sujeto debe ocuparse primero de su autoconocimiento -he aquí una labor fundamental-, debe reconocer sus anhelos, sus pre-tensiones, ser consciente de esos intereses que se forjan tras sus necesidades y según su plan de vida. El usuario precisa, entre otras disposiciones, de un trabajo de autorreflexión, interesarse primero por uno mismo, despertar un interés cognoscitivo emancipatorio que nos ofrezca ese saber que Habermas $\left(c f r .1995,41^{30}\right)$ apunta como necesario para liberar al sujeto de la dependencia de poderes hipostatizados, para el caso, de las grandes sociedades comerciales que, a través de las redes sociales, tiranizan nuestra atención. En segundo lugar, a la vez que de autoconocimiento, debe aparecer un afán de autoafirmación. Siguiendo una vez más los trabajos orteguianos sobre atención, debemos apuntar como pilar fundamental la necesidad de ser exigentes en nuestras elecciones, no solo conocedores de ellas, sino más firmes en demandar aquello que nos interesa y no sucumbir a las atracciones impresionistas. Aflora un matiz importante en este punto, aunque como hemos visto todo lo que nos es interesante capta nuestra atención, no todo lo que nos llama la atención es, en última instancia, interesante. Hay estímulos del entorno que son capaces de seducirnos por el mero hecho de estimular pulsiones más viscerales, apetencias; son estímulos que, todo y que biológicamente nos seducen, no necesariamente participan de nuestro proyecto de vida (v.g. todo lo que tiene que ver con sexo, del tipo que sea, capta inicialmente nuestra atención). Frente a ese poder atractivo de multitud de estímulos, necesitamos mayor firmeza racional, de lo que Ortega llama "espíritu" ${ }^{31}$, de lo cognitivo, de lo biográfico. Lo interesante es un tipo de atrayente que implica más que la mera pulsión instintiva, todo y que emerge del mismo fondo anímico que el resto de apetitos, en su expresión, el interés debe contar con cierta licencia espiritual, con la creencia de que aquello que nos atrae está realmente valorado y se nos presenta, al menos, como excelente; debemos exigir a lo que nos mueve a interactuar, a clicarlo, que efectivamente sume en el despliegue de nuestro proyecto de vida; debemos intentar, como dice el madrileño, no ser solamente atraídos, sino interesados (cfr. OC, V, 504). El interés conlleva la discriminación de las atracciones, la selección que se realiza sobre el instinto; es una elección tomada sobre aquellas preferencias más profundas, más íntimas y prístinas de la persona, una elección que, sustentada sobre la base de nuestro carácter, escoge aquello que más le interesa, no lo que solo le seduce, esto es, debe escoger para cada caso aquello que le resulte excelente.

Educar en ello, a nuestro juicio, es la principal tarea de la filosofía en este campo que se nos presenta aún indómito: educar para contrarrestar el adormecimiento crítico y la falta de exigencia que evidencian estas plataformas. Las redes sociales, como canales de masas, lejos de conducirnos a la emancipación social que anhelaba Vattimo, por el momento solo han dejado al descubierto una disposición a ser presas de un adormecimiento general en la agudeza crítica de nuestra salida selectiva a la realidad, una propensión a caer en el angostamiento perceptivo por la seducción de nuestros intereses. Frente a ello, junto con el establecimiento de una legislación que vele por los intereses de los usuarios y el compro-

30 De la lección ofrecida por Habermas el 28 de junio de 1965 en la Universidad de Frankfurt bajo el lema Erkenntnis und Interesse.

31 Ver «Vitalidad, alma, espíritu» (OC, II, 566). 
miso por construir espacios interactivos sobre unos principios respetuosos y democráticos, cabe un arduo trabajo de sensibilización y compromiso educativo ${ }^{32}$ para avivar o despertar el pensamiento crítico del sujeto en tanto lo que es, un ser arrojado al mundo.

\section{Referencias}

Agencia Española de Protección de Datos. (2014a). Derecho al olvido. www.agpd.es/portalwebAGPD/CanalDelCiudadano/derecho_olvido/index-ides-idphp.ph. (12/09/2016).

Agencia Española de Protección de Datos (2014b). Legislación. www.agpd.es/portalwebAGPD/canaldocumentacion/-legislacion/index-ides-idphp.php. (12/09/2016).

Bastida, Álvaro (2005): «Salvación y elegancia de la vida. La Metafísica ética de José Ortega y Gasset». En LLANO ALONSO, F. H. y CASTRO SÁENZ, A. (eds.). Meditaciones sobre Ortega y Gasset. Madrid: Tébar, pp. 55-108.

Carpintero, Heliodoro (2000): Esbozo de una Psicología según la razón vital. Madrid, España: Real Academia de Ciencias Morales y Políticas.

Carpintero, Heliodoro (1990): «Ortega y la Psicología: el caso de la atención». Revista de Occidente, $\mathrm{n}^{\circ}$. 108, pp. 49-60

Carpintero, Heliodoro (1983): «Procesos psicológicos y situación histórica en el pensamiento de Ortega». Psicopatología, no. 3, vol. 2, pp. 157-170.

Debatin, Bernhard, Lovejoy, Jennette P., Honr, Ann K., Hughes, Brittany N. (2009): «Facebook and Online Privacy: Attitudes, Behaviors, and Unintended Consequences». Journal of Computer-Mediated Communication, $\mathrm{n}^{\circ} 15$ (1), pp. 83-108.

Derrida, Jaques (1997): El mal de archivo. Una impresión freudiana. Madrid: Trotta.

Facebook (2016a): Facebook reports second quarter 2016. Results. https://investor.fb.com/ investor-news/press-release-details/2016/Facebook-Reports-Second-Quarter-2016-Results/default.aspx. (12/09/2016).

Facebook (2016b): Aboud Facebook Ads. www.facebook.com/ads/about/. (12/09/2016).

Fichte, Johann G. (2005): Ética. Madrid: Akal.

García Alonso, Rafael (1997): El náufrago ilusionado: La estética de José Ortega y Gasset. Madrid: Siglo XXI.

Habermas, Jürgen (1982): Conocimiento e interés. Madrid: Taurus.

Habermas, Jürgen (1995): Conocimiento e interés. València: UV.

Husserl, Edmund (2008): La crisis de las ciencias europeas y la fenomenología trascendental. Buenos Aires: Prometeo.

IAB Spain (2016): Estudio anual de redes sociales. iabspain.net/wp-content/uploads/downloads/2016/04/IAB_EstudioRedesSociales_2016_VCorta.pdf (12/09/2016).

International Medical Interpreters Association, IMIA. Código ético para profesionales de la información de la Salud. http://www.imia.org/pubdocs/Spanish_-Translation.pdf $(12 / 09 / 2016)$.

32 Más allá de las resistencias gubernamentales y las dificultades institucionales que la filosofía, como materia, está encontrando, existen numerosas propuestas educativas. Una muy interesante, por citar un ejemplo, es la presentada por la UNESCO en 2007 bajo el lema La Philosophie, une Ecole de la Liberté. Enseignement de la philosophie et apprentissage du philosopher: état des lieux et regards pour l>avenir. 
Iribarne, Julia (2007): De la ética a la metafísica en la perspectiva del pensamiento de Edmund Husserl. Bogotá: San Pablo.

Lacalle, Charo (2011): «La ficción interactiva. Televisión y Web 2.0». Ámbitos, nº 20, pp. 87-107.

López Molina, Antonio M. (2002): «Autorreflexión e interés emancipatorio en J. Habermas». En: A. Domínguez. Vida, pasión y razón en grandes filósofos, Cuenca: Ed. Universidad Castilla-La Mancha, pp. 355-387.

Montesó, Jorge (2016): La atención en el pensamiento de Ortega y Gasset. Castelló: Centre d'estudis antropològics ACAF.

Oficina del Comisionado de Protección de datos de Irlanda (2012): Report of Data Protection Audit of Facebook Ireland Published dataprotection.ie/viewdoc.asp?DocID=1175. (12/09/2016).

Ortega y Gasset, José (2004a): Intimidades. Obras Completas, II. Madrid: Taurus.

Ortega y Gasset, José (2004b): Vitalidad, alma, espíritu. Obras Completas, II. Madrid: Taurus.

Ortega y Gasset, José (2005a): La deshumanización del arte e ideas sobre la novela. Obras Completas, III. Madrid: Taurus.

Ortega y Gasset, José (2005b): Estudios sobre el corazón. Obras Completas, IV. Madrid: Taurus.

Ortega y Gasset, José (2006): Estudios sobre el amor. Obras Completas, V. Madrid: Taurus. Ortega y Gasset, José (2008): ¿Qué es filosofía? Obras Completas, VIII. Madrid: Taurus.

Ortega y Gasset, José (2009): Prólogo para alemanes. Obras Completas, IX. Madrid: Taurus. Pfänder, Alexander (1913): Zur Phänomenologie der Gesinnungen. Jahrbuch für Philosophie und phänomenologische Forschung. Hale.

Rodríguez Huéscar, Antonio (1985): Perspectiva y verdad. Madrid: Alianza.

Scheler, Max F. (2001): Ética: nuevo ensayo de fundamentación de un personalismo ético. Madrid: Caparrós.

UNESCO (2011): La filosofía, una escuela de la libertad. Enseñanza de la filosofía y aprendizaje del filosofar: la situación actual y las perspectivas para el futuro. México: UNESCO.

Vattimo, Gianni (1990): La sociedad transparente. Barcelona: Paidós. 
